Apresentação

Música e cena: um imenso intercampo de atividades e reflexões

Marcus Mota

Revista do Laboratório de Dramaturgia - LADI - UnB - V. 2 e 3, Ano 1 


\title{
Música e cena: \\ um imenso intercampo de atividades e reflexões
}

\author{
Marcus Mota \\ Editor-Chefe da Revista Dramaturgias \\ Professor Universidade de Brasília
}

Diretor do LADI

Este segundo número da Revista Dramaturgia possui uma série de textos dedicados às relações entre Teatro e Música. Entre artigos originais e traduções de ensaios, o dossiê procura apresentar as pesquisas e reflexões de investigadores e artistas a partir de suas demandas estéticas e intelectuais.

Com isso, mesmo não sendo possível abarcar as mais diversas possibilidades das tensões entre cena e música, há a oportunidade de mostrar um pouco da multiplicidade de abordagens e objetos que artistas e pesquisadores do Brasil e de outros países puderam identificar em relatos de experiências, reconstruções de espetáculos, propostas estéticas, análise de obras, exame e discussão de metodologias. Antes de tudo, todos compartilham da preocupação de se pensar o som em performance, articulado por atores, cantores e músicos.

Há uma longa história sobre as relações entre teatro e música. Pensando de outra maneira, um teatro centrado na palavra falada, ou uma cena unidimensional, é coisa bem recente. Essa redução, na verdade, é uma réplica estética de uma abstração filológica: na transmissão de grandes textos do passado, houve a contínua separação entre conteúdo registrado e contexto performativo.

Prova disso são as várias dramaturgias multissensoriais em diversas culturas como as encenações de mitos nos festivais antigos egípcios e a tragédia pré-colombina Quiché Vinak, que integram canto, dança, ação e palavra ${ }^{1}$.

O caso do "Teatro grego antigo", tido como ponto zero da dramaturgia ocidental, é bem esclarecedor. Como os teatros Egípcio e Maia supracitados, e em comum como o teatro Sanscrítico e o Nô, a dramaturgia ateniense integrava diversas artes, habilidades, tradições performativas. A sua transmissão textual e a recepção dessa transmissão favoreceram uma imagem que é a que temos hoje quando vamos a uma livraria ou biblioteca e consultamos apenas o libreto, o roteiro com a ordem das cenas e o conjunto das falas.

O incrível é que, se um ramo da recepção dessa dramaturgia desembocou no teatro

1 Sobre textos da dramaturgia egípcia antiga, v. Escrito para a Eternidade, de Emanuel Araújo (Editora UnB, 2000). O famoso 'Papiro dramático de Ramesseum' contém texto e ilustrações (storyboard) de ceremônia palaciana de coroação, bem analisados ainda por E. Araújo em sua tese Papiro dramático de Ramesseum (USP, ECA, 1974), e por David Lorand que em seu trabalho Le papyrus dramatique du Ramesseum:Études des structures de la composition (Peeters, 2009, defende que o documento é uma texto propaganda real do faraó Sesóstris I. Além dessas cenas dramáticas, temos os textos com personagens, rubricas, diálogos em volta do ciclo de Hórus, que se aproximam das "passion plays" medievais. Sobre o tema, v. Performance and Drama in Ancient Egypt (Bristol Classics Press, 2006), de Robyn Gillam. 
literário da centralidade da palavra falada em cena, como se vê no Classicismo francês, outro fez irromper a Ópera ${ }^{2}$. É por que nesses libretos da dramaturgia ateniense, nesses fósseis de uma ampla e generalizada cultura performativa, temos marcas de produção de ações sonoramente orientadas, como cantos, danças e contracenações ritmizadas ${ }^{3}$.

O desenvolvimento da Ópera foi uma interpretação compensatória desses fosséis: transformou o silêncio do texto escrito em superabundância musical. Assim, a partir da transmissão e recepção dos fósseis da Cultura Performativa da Antiguidade (Mousiké), nos deparamos com situações opostas e complementares: a centralidade da palavra, tendo como margens o silêncio e a música; e a superabundância da música, tendo como margens o gesto e o controle rítmico-tonal da fala.

Além dessas tensões, há diversos casos em que os encontros entre reduções e excessos se fazem presentes. O caso de Shakespeare é sintomático. Suas últimas produções são contemporâneas da criação da Ópera ${ }^{4}$. Ao mesmo tempo, é perceptível nessas produções finais, um maior uso de sonoridades, de fantasia, de efeitos sinestéticos. Não é em vão que muitas dessas mudanças estão intimamente relacionadas com um maior diálogo de Shakespeare com experimentos escriturais de recepção da Cultura Grega - os chamados Romances gregos, que transitavam entre drama e narrativa - , e a aquisição do Teatro Blackfriars, um antigo mosteiro com maiores possibilidades acústicas que o The Globe ${ }^{5}$.

2 As discussões da Camerata Florentina, a partir do terceiro quarto do século XVI, desemboram nos experimentos de Jacopo Peri (Dafne,em 1597; Euridice, em 1600) e de Monteverdi (Orfeo, 1607). Para a Camerata Florentina, v. a obra organizada por C. Palisca The Florentine Camerata: Documentary Studies and Translations (Yale University Press, 1989). V. ainda Music and Theatre From Poliziano to Monteverdi, de Nino Pirrotta e Elena Povoledo (Cambridge University Press, 1982) Sobre o Classicismo francês, temos em mente autores como Corneille (1606-1684) e Racine (1639-1699). Tanto quanto as obras, é importante a racionalização da herança aristotélica, nem tão sistemática quanto se pensa, como bem demonstra J. D. Lyons em seu livro Kingdom of Desorder: The Theory of Tragedy in Classical France ( Pordue University Press, 1999). A partir de sua tradição, Florence Dupont nos oferece uma ácida critica desse aristotelismo autoritário, centrado da palavra plena e não na espetacularidade multidimensional da dramaturgia ateniense no livro Aristote ou el vampire du théâtre occidental (Aubier, 2007).

3 É imensa a bibliografia sobre o tema. Indico o meu livro A dramaturgia musical de Ésquilo (Editora UnB, 2008); os dois livros de William C. Scott - Musical Design in Sophoclean Theater (Dartmouth, 1996) e Musical Design in Aeschylean Theater (Dartmouth, 1984); e o livro de Aires M. R. Pereira Mousiké: Das origens ao drama de Eurípides (Fundação Gulbenkian, 2001).

4 Como Timon de Atenas (1606), Péricles (1607-1608), Conto de Inverno (1609), Cimbelino (1610) e A tempestade (1611).

5 Sobre Shakesapeare e a tradição clássica, v. C.Cobb, The Staging of Romance in Late Shakespeare: Text and Theatrical Technique. Associated University Presses, 2010; C. Gesner, Shakespeare and the Greek Romance. University Press of Kentucky. 1982; C. Martindale e A Booth (Eds.) Shakespeare and the Classics. Cambridge University Press, 2004; B. Mowat, The Dramaturgy of Shakespeare's Romances. The Romances as Open Form Drama. The University of Georgia Press. 1976. Sobre o papel do teatro Blackfriars no 'musificação' do teatro Shakesperiano v. o livro de David Lindley Shakespeare and the Music (Arden/Thomson Learning, 2006). A questão é ampla: passa não apenas pela publicação das partituras das canções das obras de Shakespeare como na coletânea de Ross Duffin Shakespeare's Songbook (W.W. Norton, 2004), que teve sua réplica nacional na obra William Shakespeare: As canções Originais de Cena, de C. Zwilling( Annablume, 2010). Além do 
O que temos aqui é uma dramaturgia que, mesmo não atravessada por cenas cantadas ou por acompanhamentos instrumentais, está diretamente relacionada com a exploração de experiências e parâmetros psicoacústicos. Isso nos projeta o seguinte paradoxo: podemos ter dramaturgia musical em "obras que não são musicais" propriamente ditas. Uma obra pode não ter 'música', mas se organizar a partir de obras da tradição dramático-musical. Pois, já que não desligamos nossos sentidos, participamos globalmente tanto de uma pantomima, quanto de uma ópera, o que nos leva a explorar de jogos multissensoriais na forma como a obra é performada e organizada em sua sucessão de cenas e referências.

Creio que tal discussão além dos gêneros, presente na dramaturgia tardia de Shakespeare, projeta o deslocamento da necessidade de se identificar a música da peça para a percepção de seus sons, de sua "musicalidade"6.

Dessa forma, a questão da dramaturgia musical ou da musicalidade das obras nos impulsiona para conceber a amplitude da experiência cênica, a complexidade de seus meios, efeitos e possibilidades.

O teatro moderno e contemporâneo, reagindo contra o logofonocentrismo cênico, explode em interfaces com a música e com a dramaturgia ateniense. Vemos a musicalidade como modelo para interpretação nos escritos de Stanislávsky - ele mesmo no fim de sua vida criando Estúdios ou oficinas específicas de interpretação para cantores -; a dramaturgia multissensorial de Meyerhold; e as propostas de Brecht a partir de o debate com a Ópera de seu tempo ${ }^{7}$.

Por outro lado, em plano paralelo, vemos mutações no campo operístico, desde as ideias e as obras de Wagner, passando por experimentos que se seguiram à Segunda Grande Guerra tanto na realização de espetáculos que se valem das ampliações estéticas do teatro, da dança e das novas tecnologias, quanto na remontagem e reprocessamento de obras do cânone operístico.

Digno de nota é, entre tantos empreedimentos, a discussão produzida pela Opera

esforço compilatório de fontes, presente também em Shakespeare's Songs Restored: The Literary Impact of Original Music and Singers, de Catherine Henze (Routledge, 2016), é preciso também discutir questões da renovação da tradição dramático-musical, as tensões entre teatro e músi$\mathrm{ca}$, e os contextos de novas explorações dessas tensões. Na obra supracitada de David Lindley e no Music in Shakespeare. A Dictionary, de Christopher Wilson (Arden/Bloomsbury, 2014), assim como noutra obra deste mesmo autor, Shakespeare’s Musical Imagery (Bloomsbury, 2011), há subsídios para tais ampliações temáticas.

6 Veja-se a discussão em torno de Beckett, em Beckett and Musicality, organizado por Sara J. Bailes e Nicholas Till ( Routlegde, 2014).

7 Muitos desses autores e questões são discutidos por David Roesner em seu livro seminal Musicality in Theatre: Music as Model, Method and Metaphor in Theatre-Making (Routledge, 2014). Consultar ainda, o volume coletivo Musique et Dramaturgie. Esthétique de la représentation ao XXe.siècle, organizado por Laurent Feneyrou (Publications de La Sorbonne, 2003); e o outro volume coletivo, organizado por Giordano Ferrari, La musique et la scène. L'Écriture musicale et son expression. Scénique au XXe. Siècle (L’Harmattan, 2006). Geraldo Martins produziu uma tese de doutoramento sobre a dramaturgia musical de Brecht: Dramaturgia, Gestus e Música: estudos sobre a colaboração entre Bertolt Brecht, Kurt Weill e Hanns Eisler entre 1927 e 1932 (Universidade de Brasília, 2015). Link : http://repositorio.unb.br/handle/10482/18099. 
America em 1983, em busca de alternativas na época para a estagnação das montagens de óperas nos Estados Unidos. Entre compositores, diretores, produtores consultados, foi apontada a necessidade de produção de novos espetáculos e de estratégias para que essas novas obras enfrentassem suas diversas etapas e atividades de composição, realização, recepção, e produção ${ }^{8}$.

Enfim, a partir do horizonte e amplitude que as relações entre som e cena nos colocam, temos muitas questões abertas.

Como primeiro texto, temos o capítulo de abertura do livro The New Music Theater: Seeing the Voice, Hearing the Body (Oxford University Press, 2008), de Eric Salzman e Thomas Desi, gentilmente cedido por seus autores e por sua casa editoral para esta publicação. O "pioneiro" livro busca trazer para o debate as noções e experiências de dramaturgia musical após os impulsos de novas produções da segunda metade do século passado ${ }^{9}$.

Nesse sentido, em sequência, os textos de Luigi Nono são fundamentais para documentar este encontro entre novas formas de se fazer dramaturgia musical no teatro e na música. Agradeço e muito aos pesquisadores do CESEM (Centro de Estudos de Sociologia e Estética Musical- Lisboa) Mário Vieira de Carvalho e, especialmente, a Paulo de Assis pelo cessão do textos para esta revista ${ }^{10}$.

Após este primeiro momento, o dossiê temático se abre em diversas frentes: drama-

Após o textos do dossiê, temos a seção de textos dedicadas à memória das produções do LADI. O Laboratório de Dramaturgia da UnB desde 2001 vem trabalhando com diversas tradições de espetáculos dramático-musicais. Tivemos uma fase de remontagem de obras do repertório operístico entre 2004 e 2006, com encenações, por exemplo, de Bodas de Fïgaro, de Mozart (2004), Carmen, de Bizet (2005). Depois montagens originais a partir da releitura de textos literários como Saul (2006) e Caliban (2007) ou de musicalidades contemporâneas, como a ópera hip-hop No muro (2009).

Para este número da Revista Dramaturgias disponibilizamos material em torno do processo criativo e realização da obra David (2012), obra que, como No Muro (2009), trabalha na interface entre pesquisa e uma produção que escapa dos moldes de baixo custo do Teatro Universitário. Dentro do know-how em dramaturgia musical em contínua elaboração no LADI, não bastam apenas os apectos de composição, realização (atuação

8 A obra coletiva denomina-se Perspectives: Creating and Producing Contemporary Opera and Musical Theater (Opera America, 1983). A estagnação do repertório operístico a partir da frequência pela qual as mesmas óperas são encendas, foi estudada por Hervé Lacombe em Géographie de l'opera au XXe siècle (Fayard, 2007).

9 Para acessar materiais do compositor e pesquisador Eric Salzman, http://www.ericsalzman.com . Para acessar materiais do diretor e encenador Thomas Desi, v. http://www.thomasdesi.com .

10 Link CESEM: http://cesem.fcsh.unl.pt . 
e cenificação) e recepção: a produção dialoga e abarca todos os supracitados aspectos. A amplitude de uma dramatugia musical se torna perceptível na amplitude de seus recursos, procedimentos e tarefas.

Continuando seu diário nesta revista, o multiartista Hugo Rodas, amigo, mestre e companheiro de tanta jornadas, nos fala de sua relação com a música e da musicalidade com a qual ele organiza suas produções.

Em seguida, temos duas traduções: a primeira, $A$ música e a encenação, de Adolphe Appia, que será apresentada em partes durante este e os próximos números da Revista Dramaturgias- traduação realizada pelo artista e pesquisador Flávio Café; a segunda tradução é de nosso amigo e companheiro editorial Carlos Alberto da Fonseca que, ainda trabalhando na esperada e monumental versão do original sanscrítico para o português do Natyasastra, brinda-nos com as canções de Kurt Weill. Que aperitivo!

Como presente para essa edição, publicamos o livro inédito do compositor, músico e meu professor na Berklee University Jerry Gates. Trata-se de um conjunto de exercícios de aplicação de técnicas dodecafônicas para práticas compositivas ${ }^{11}$.

Encerramos o volume com artigo do grande especialista em Beckett Stanley Gontarsky, da Florida State University, gentilmente traduzido pela professora, atriz e pesquisadora Laura Moreira.

Agradeço a todos os colaboradores desta edição, os quais prontamente se disponibilizaram em enviar seus textos.

Brasília, Novembro-Dezembro de 2016.

11 Link: http://www.jerrygatesmusic.com . 